\title{
Alcohol intake and risk of renal cell carcinoma: a meta-analysis of published case-control studies
}

\author{
Guang Cheng, Liping Xie
}

Department of Urology, The First Affiliated Hospital, School of Medicine, Zhejiang University, Hangzhou, Zhejiang Province, China

Submitted: 29 August 2010

Accepted: 24 December 2010

Arch Med Sci 2011; 7, 4: 648-657

DOI: 10.5114/aoms.2011.24135

Copyright @ 2011 Termedia \& Banach

\begin{abstract}
Introduction: While some studies have indicated that alcohol intake is associated with a decreased risk of renal cell carcinoma, others have not. We conducted a meta-analysis of case-control studies to provide a quantitative assessment of the association between alcohol intake and the risk of renal cell carcinoma.

Material and methods: We identified studies by a literature search of PubMed and review of references of relevant articles. Both the fixed and random-effects models were used to obtain the summary risk estimates associated with the highest versus the lowest consumption categories depending on the heterogeneity of effects among studies. Dose-response meta-analysis was performed for studies reporting categorical risk estimates for a series of exposure levels.

Results: Fifteen studies were included in this meta-analysis. An inverse association between alcohol consumption and renal cell carcinoma was observed in both the overall alcohol intake group (OR 0.67, 95\% Cl 0.62-0.73) and subgroups stratified by sex, study design, geographical region, specific beverages and alcohol assessment. The dose-response meta-analysis showed that an increase in alcohol consumption of $12 \mathrm{~g}$ of ethanol per day was associated with a $5 \%$ statistically significant decreased risk of renal cell cancer.

Conclusions: High alcohol consumption exhibits a preventive effect for renal cell carcinoma in a dose-response manner. Further efforts should be made to clarify the underlying biological mechanisms.
\end{abstract}

Key words: alcohol drinking, alcoholic beverages, ethanol, kidney neoplasms, metaanalysis.

\section{Introduction}

Alcohol consumption is increasing in many countries and is an important cause of cancer worldwide [1]. A causal link has been established between alcohol consumption and cancers of the upper alimentary tract, liver, colorectum, and female breast [2]. Modifying alcohol consumption could be part of a prevention strategy of cancer through lifestyle changes.

Increasing incidence rates of renal cell carcinoma (RCC) have been reported worldwide [3]. Reasons for this phenomenon could be explained by both improvement in diagnostic workup and environmental factors. Smoking, obesity and hypertension are consistently associated with an increased risk of RCC [4-6], and the rising prevalences of obesity and hypertension likely have contributed to the upward cancer trends. The

\author{
Corresponding auhor: \\ Dr. Li-Ping Xie \\ Department of Urology \\ The First Affiliated Hospital \\ School of Medicine \\ Zhejiang University \\ Qingchun Road 79 \\ Hangzhou 310003 \\ Zhejiang Province, China \\ Phone: +86 57187236735 \\ Fax: +86 57187072577 \\ E-mail: \\ xielp@zjuem.zju.edu.cn
}


association between alcohol consumption and the risk of RCC has also been widely investigated, yielding inconclusive results. Most of the earlier case-control [7-13] and cohort studies [14-18] have shown no association, while recent prospective cohort studies [19-23] found a reduced incidence of RCC in alcohol drinkers.

Recently, a pooled analysis of 12 cohort studies showed that moderate alcohol consumption was associated with a decreased risk of RCC [24]. The purpose of the present study was to re-examine the epidemiological evidence regarding the association between alcohol consumption and the risk of RCC by summarizing the results of published case-control studies, including dose-response metaanalyses, to quantify the strength of this association.

\section{Material and methods}

\section{Selection of studies}

We identified publications in PubMed using alcohol, renal cell carcinoma, renal cell cancer, kidney cancer and case-control as keywords. Hand searches were also performed via cited references from the identified articles and reviews. The criteria for inclusion were (i) case-control studies evaluating the relationship between alcohol consumption and RCC; (ii) published in English between 1980 and March 2010; (iii) providing odds ratio (OR) estimates and corresponding 95\% confidence intervals $(95 \% \mathrm{Cl})$, or information allowing us to compute them. In studies with overlapping patients or controls, the latest study with the largest sample size was included.

\section{Data extraction}

For each study, data were extracted for the first author, year of publication, the country in which the study was conducted, study design, number of cases, number and range of categories of exposure, adjusted effects estimates, types of alcohol exposure, adjusted covariates and exposure assessment. We extracted the maximally adjusted ORs and Cls. When sex-stratified ORs were provided in a study, the ORs were independently involved in the overall meta-analysis.

\section{Statistical analysis}

We first quantified the associations of alcohol with RCC risk using meta-analysis of OR estimates associated with the highest versus the lowest category of alcohol intake using fixed- and randomeffects models that included a term for heterogeneity. Second, subgroup analyses were performed according to study design (hospitalbased or population-based case-control studies), sex (men or women), geographical region (US/Canada or Europe), alcohol assessment (interview or questionnaire) and type of alcohol beverages (beer, wine or spirits).

For the dose-response meta-analysis, we estimated study-specific dose-response slopes from the correlated natural log of the ORs across categories of alcohol consumption using the method proposed by Greenland and Longnecker [25]. We converted all measures into grams of alcohol per day on the widely used estimation that a standard drink contains $12 \mathrm{~g}$ of alcohol regardless of alcohol type unless it was defined in the study population or the geographical area. The level of alcohol consumption was assigned from each study to these categories based on the calculated midpoint of alcohol consumption. When the highest category was open-ended, we assumed the width of the interval to be the same as in the preceding category.

We quantified the extent of heterogeneity using Q-test [26] and $R$ score [27] and statistical significance was considered when $p<0.05$. Metaregression analysis was used to explore the influence of study design, geographical region, alcohol assessment, and publication years in the heterogeneity. Publication bias was assessed using the tests of Egger [28] and Begg [29]. All statistical analyses were done with Stata Statistical Software, version 10.0.

\section{Results}

\section{Characteristics of studies}

We identified 24 articles [7-12, 30-47] that evaluated the association of RCC incidence and alcohol intake published between 1980 and March 2010. Four articles [10, 11, 42, 43] did not provide sufficient information to estimate a summary odds ratio and its 95\% confidence intervals. One casecontrol study published results in two different articles [38, 44], while two studies published results in three different articles each [31, 37, 40, 46-48], and we extracted the latest and largest data sets from them [31, 37, 38, 40]. Of the fifteen selected studies, six were hospital-based case-control [7, 12, $30,33,36,38]$, and nine were population-based case-control studies [8, 9, 31, 32, 34, 35, 37-40] (Table I), including a total of 9284 cases. Nine of these studies were conducted in the United States/Canada [7-9, 30, 32, 34, 37, 39-41], while 5 were in Europe $[12,33,35,36,38]$ and 1 in multiple countries [31]. Nine articles reported the associations between consumption of specific alcoholic beverages (beer, wine or spirits) and the risk of RCC [9, 30, 31, 34-40]. Information on alcohol consumption was obtained by interview, selfadministered questionnaire or both techniques. 


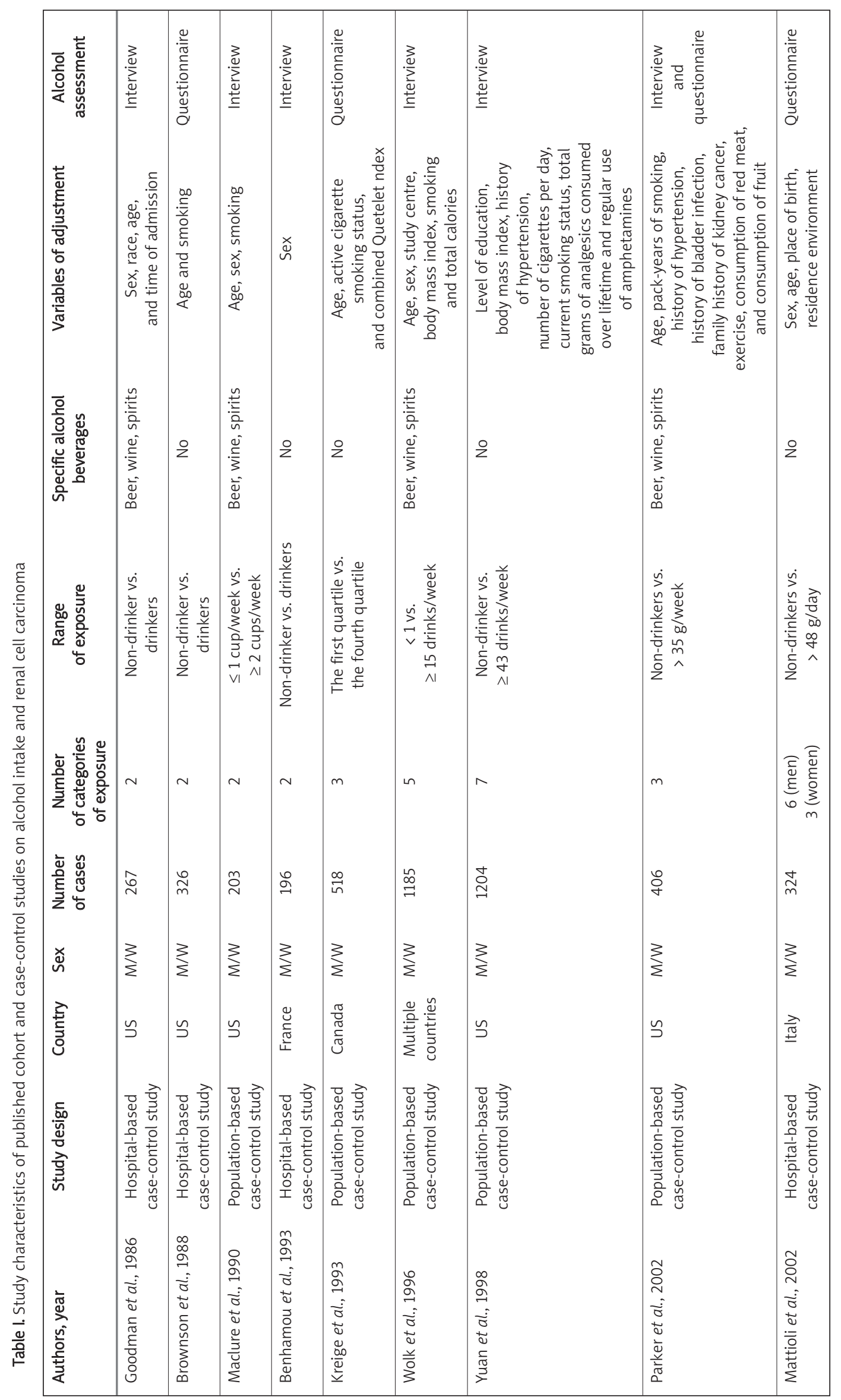




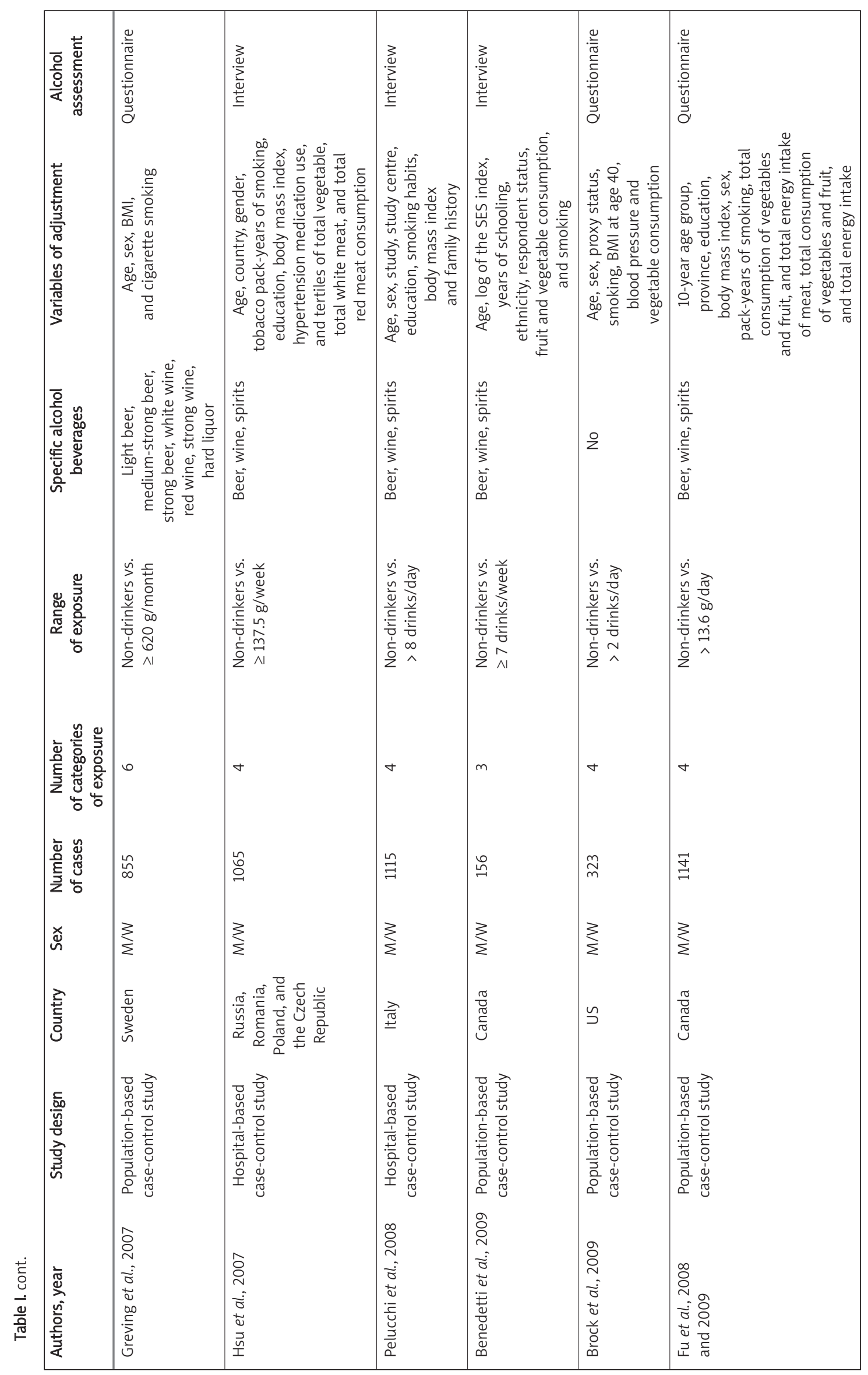


Among 15 case-control studies, seven reported significantly decreased risks of RCC in drinkers as compared with non-drinkers [30, 31, 34, 35, 37, 38, 40,41 , whereas seven studies found no association $[7,8,12,32,33,36,41]$. A study conducted by Maclure et al. [9] provided odds ratios for three alcoholic beverages but no data on overall alcohol intake.

\section{Highest versus lowest}

In Figure 1 we present the overall ORs of RCC comparing the highest versus the lowest alcohol consumption categories. When all these casecontrol studies were analysed together, we observed a statistically significant 30\% reduced risk of RCC. In analysis by study design, population-based case-control studies (OR $0.65,95 \%$ Cl 0.52-0.79) reported a lower risk of RCC in drinkers compared to hospital-based case-control studies (OR 0.78, $95 \% \mathrm{Cl} 0.65-0.91)$. The results were heterogeneous across case-control studies $\left(P_{\text {Het }}=0.02, I^{2}=48.2 \%\right)$. There was no evidence of heterogeneity among hospital-based case-control studies, but some evidence in population-based studies.

In Table II, we assessed associations separately for sex (men or women), geographical region
(US/Canada or Europe) and alcohol assessment (interview or questionnaire). The OR estimates from subgroup analyses varied little, showing that alcohol consumption was consistently associated with a decreased risk of RCC. In analysis by specific beverages (Figure 2), we also found a significantly decreased risk of renal cancer for intake of beer, wine and spirits. There was no evidence of significant publication bias either with Egger's or Begg's test in any subgroup.

\section{Dose-response analysis}

Nine studies [32-41] were included in the doseresponse analysis of the association between alcohol intake and risk of RCC. We excluded 4 studies with only 2 categories of alcohol consumption [7, 9, 12, 30] and one publication that did not provide the number of cases and controls, and one without exact dosage limits of alcohol for each stratum. Figure 3 shows the dose-response relationship between risk of RCC and alcohol consumption. There was a $5 \%(95 \% \mathrm{Cl}$ $3 \%-7 \%$ ) decrease of risk of RCC for an increase of $12 \mathrm{~g}$ alcohol intake (approximately $1 \mathrm{drink}$ ) per day. The result was heterogeneous $(p<0.01)$.

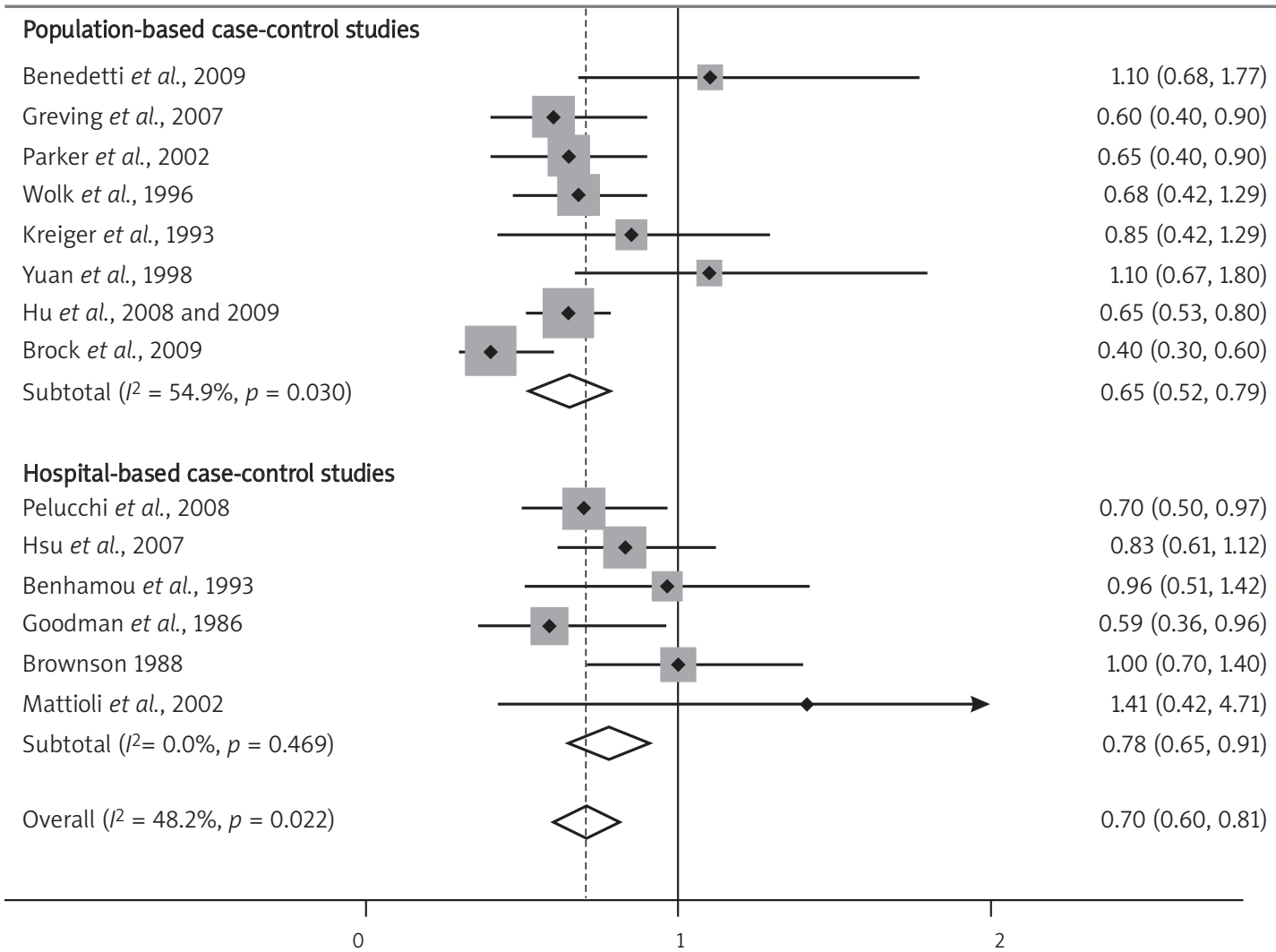

Figure 1. A forest plot showing risk estimates from case-control studies estimating the association between overall alcohol consumption and risk of renal cell carcinoma 
Table II. Summary of pooled risk ratios of renal cell carcinoma by sex, geographical region, type of alcoholic beverages, body mass index, and smoking status

\begin{tabular}{|c|c|c|c|c|c|}
\hline Subgroup & $\begin{array}{l}\text { Number } \\
\text { of studies }\end{array}$ & $\begin{array}{l}\text { Pooled OR } \\
(95 \% \mathrm{Cl})\end{array}$ & $\begin{array}{c}P_{\text {heterogeneity }} \\
\text { (R score) }\end{array}$ & $\begin{array}{l}\text { Egger's test } \\
\text { Value of } p\end{array}$ & $\begin{array}{l}\text { Begg's test } \\
\text { Value of } p\end{array}$ \\
\hline All studies & $14[7,8,12,13,30-37,39-41]$ & $0.70(0.60,0.81)$ & $0.02(48.2 \%)$ & 0.17 & 0.32 \\
\hline \multicolumn{6}{|l|}{ Sex } \\
\hline Men & $9[7,8,12,30,31,33,34,37,38]$ & $0.80(0.69,0.91)$ & $0.47(0)$ & 0.66 & 0.60 \\
\hline Women & $9[7,8,12,30,31,33,34,37,38]$ & $0.61(0.47,0.76)$ & $0.56(0)$ & 0.49 & 1 \\
\hline \multicolumn{6}{|c|}{ Geographical region } \\
\hline Europe & $5[12,33,35,36,38]$ & $0.73(0.60,0.87)$ & $0.55(0)$ & 0.38 & 0.46 \\
\hline US/Canada & $8[7,8,30,32,34,37,39-41]$ & $0.71(0.54,0.87)$ & $0.01(64.8 \%)$ & 0.40 & 0.62 \\
\hline \multicolumn{6}{|c|}{ Alcohol assessment } \\
\hline Interview & $7[12,30-32,36,38,39]$ & $0.75(0.64,0.87)$ & $0.43(0)$ & 0.30 & 0.76 \\
\hline Questionnaire & $6[7,8,33,35,40,41]$ & $0.62(0.44,0.79)$ & $0.02(64.6 \%)$ & 0.57 & 0.57 \\
\hline
\end{tabular}

\section{Meta-regression analysis}

We also performed meta-regression analysis to explore the influence of publication year, geographical region, study design, and method of alcohol assessment on the heterogeneity. However, none of the above was identified as a possible source of heterogeneity among all the included studies.

\section{Discussion}

In this meta-analysis we have observed an inverse association between alcohol intake and the risk of RCC. This finding is consistent with the previous pooled analysis by Lee et al. [24], which used the patient-level data and provided more convincing results and deeper analysis. However, in that study the case-control studies were not included. We included all the case-control studies so far for a total of 9,284 RCC cases. Our results showed that case-control studies, which may be subject to selection and recall bias, also provided support for a negative relationship between alcohol consumption and RCC. There was no evidence of heterogeneity among studies included in this analysis. Furthermore, we performed a metaanalysis of dose-response relationship between alcohol intake and the risk of RCC. An increase in

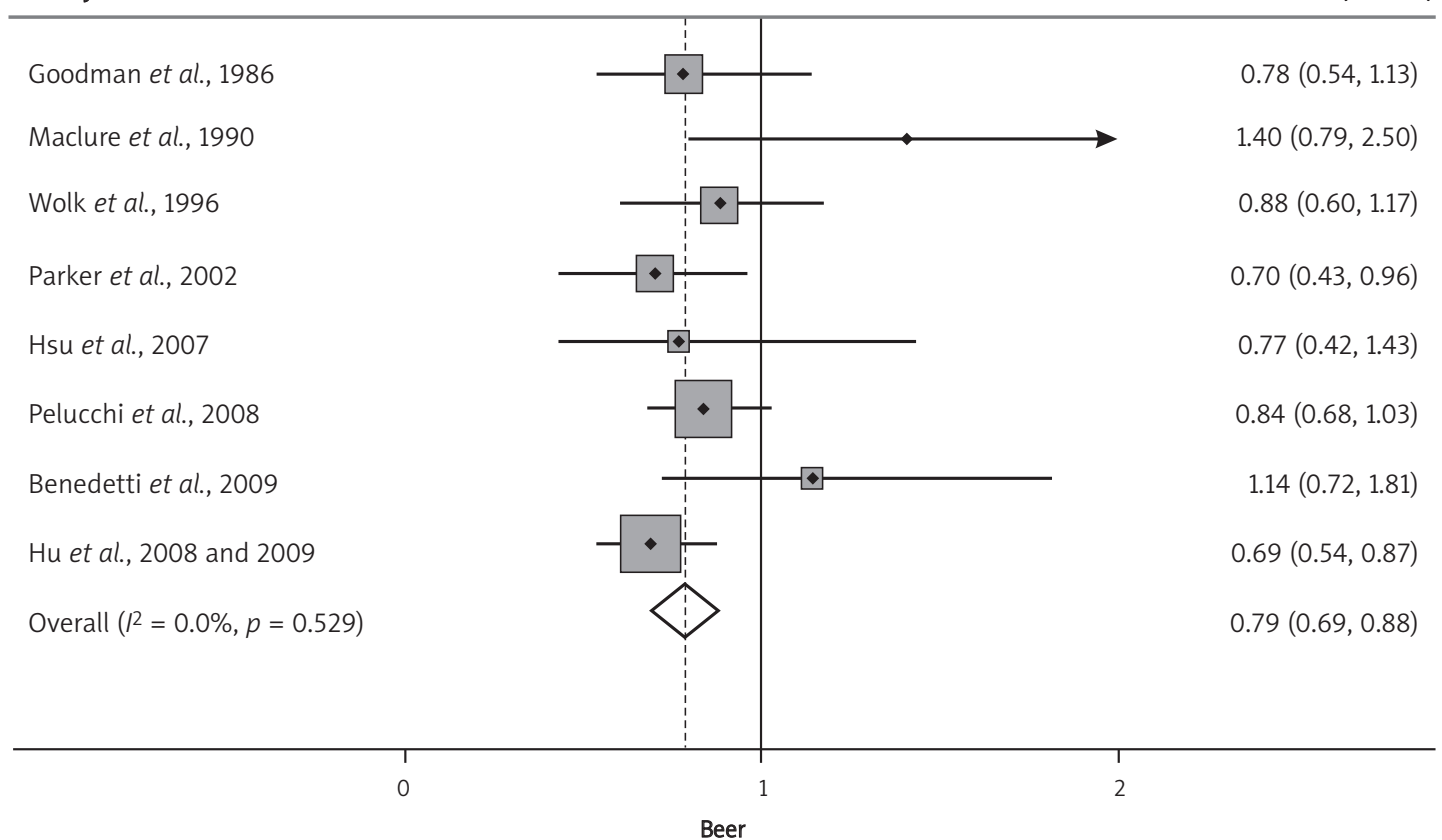

Figure 2. Forest plots showing the odds ratio of each study and the pooled odds ratios for specific alcoholic beverages 


\begin{tabular}{ll}
\hline Goodman et al., 1986 & $0.66(0.45,0.96)$ \\
Maclure et al., 1990 & $0.95(0.30,3.00)$ \\
Wolk et al., 1996 & $0.33(0.18,0.47)$ \\
Parker et al., 2002 & $1.06(0.58,1.54)$ \\
Hsu et al., 2007 & $1.05(0.51,2.08)$ \\
Pelucchi et al., 2008 & $0.50(0.27,0.92)$ \\
Benedetti et al., 2009 & $0.91(0.52,1.59)$ \\
Overall $(12=66.0 \%, p=0.004)$ & $0.73(0.55,0.96)$ \\
\hline
\end{tabular}

Maclure et al., 1990

Wolk et al., 1996

Parker et al., 2002

Hsu et al., 2007

Greving et al., 2007

Pelucchi et al., 2008

Benedetti et al., 2009

Hu et al., 2008 and 2009

Overall $(R=76.3 \%, p=0.000)$
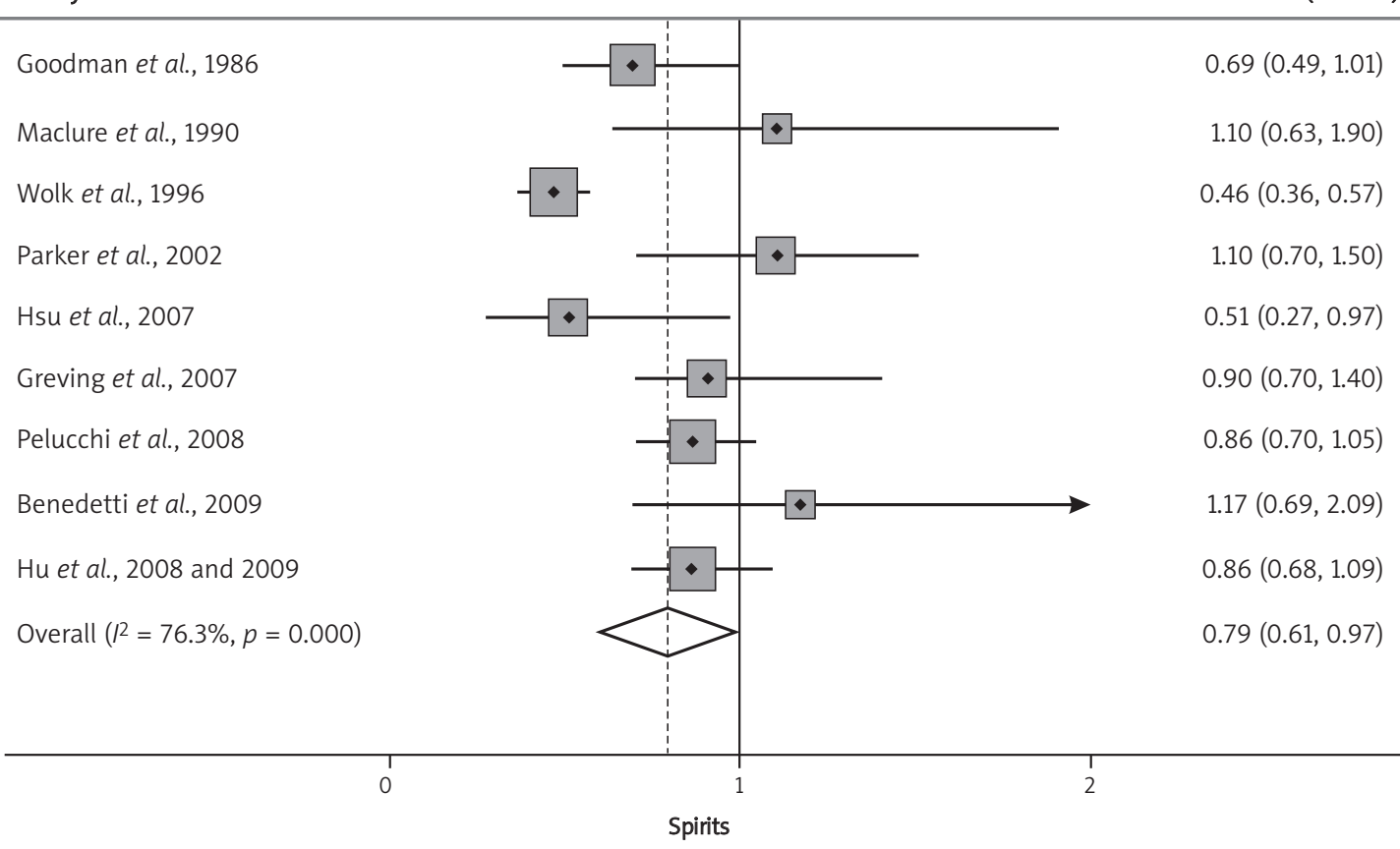

Figure 2. Cont.

alcohol consumption of $12 \mathrm{~g}$ of ethanol per day was statistically significantly associated with a $5 \%$ decrease in risk of RCC.

Our results from subgroup analyses suggested that an inverse relationship between alcohol intake and risk of RCC was seen in both men and women, and a stronger association was observed in women compared to men, although the difference in risk estimate was not statistically significant. This gender-specific association may suggest an underlying hormonal mechanism. There is some evidence that oestrogens increase risk of RCC [49, 50]. However, the data regarding effects of alcohol on oestrogen levels are inconsistent [51, 52], and recent studies suggest that alcohol's favourable effect does not appear to involve hormonal 
mechanisms [53]. The summarized OR estimates were not statistically different across different alcoholic beverage types, indicating that the negative association is attributable to ethanol intake itself rather than to a specific beverage, though certain ingredients in beer and wine, such as xanthohumol and resveratrol, have been demonstrated to possess cancer chemopreventive properties $[54,55]$. Our results also suggest that the association between alcohol consumption and RCC was not modified by different geographical regions or methods of alcohol assessment.

Several biological mechanisms for the negative relationship of alcohol consumption with the development of RCC have been proposed. One potential explanation is that the diuretic effect of alcoholic beverages may reduce the concentration of carcinogens and decrease the time that carcinogens stay in the kidney. This hypothesis could be verified by investigating the relationship of total fluid intake and RCC. However, a pooled analysis of 2 cohorts detected no association and a population-based case-control study found a positive relationship between total fluid intake and risk of RCC $[22,40]$. Enhanced insulin sensitivity might be a mechanism by which alcohol intake exerts its protective effect against RCC. Obesity and diabetes are risk factors for RCC $[56,57]$, and light to moderate alcohol intake is associated with improved insulin sensitivity [58]; thus it is possible that insulin is a potential intermediate component in the association between alcohol consumption and RCC. It would be informative to determine whether the protective effect exists in patients with different insulin sensitivity levels, and well-designed cohort studies are needed to further clarify the consistency within diabetic and non-diabetic subjects.

Several potential limitations of our study need to be considered. First, as this meta-analysis is based on case-control studies, the possibility of bias and uncontrolled or residual confounding factors cannot be excluded, although we extracted the maximally adjusted ORs, which have been controlled for variables that might be related to RCC in most of the studies. However, different studies may have adjusted for different covariates, which could probably bias the results. Second, we did not attempt to uncover unpublished observations, which could bring a publication bias, even though no significant evidence of a publication bias was observed in Egger's and Begg's test. Third, both volume of alcohol consumption and patterns of drinking have been shown to influence the alcoholrelated burden of disease, while most of the included studies did not provide data on alcohol intake over time or life drinking patterns.

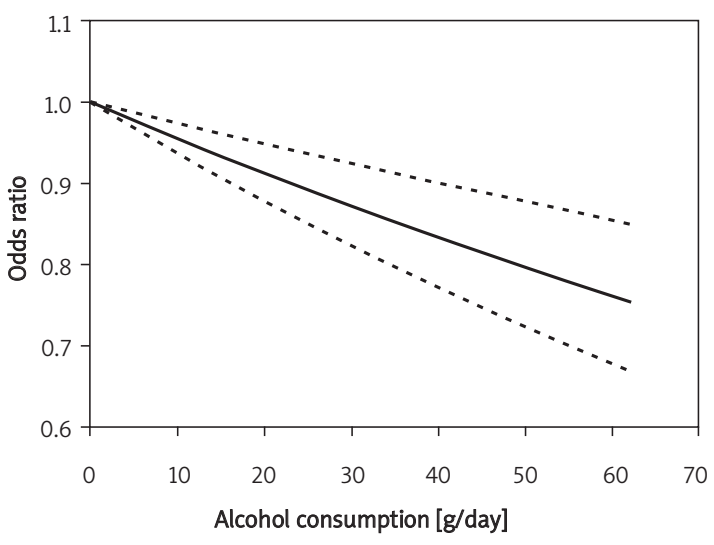

Figure 3. Odds ratio for renal cell carcinoma by doses of alcohol intake based on the results of the doseresponse meta-analyses. Solid line represents the estimated odds ratios and the dotted lines represent the $95 \%$ confidence intervals

Consequently, we did not have sufficient data to evaluate the risk of RCC associated with these other dimensions of alcohol intake.

In conclusion, this study applied a detailed metaanalytic approach for combining OR estimates from case-control studies on the relationship between RCC incidence and alcohol consumption. We found that high alcohol consumption was consistently associated with a lower risk of renal cell cancer when stratified by sex, study design, geographical region and alcoholic types, and decreased risk for RCC in a dose-response manner. Future research to determine the likely biological mechanism is warranted.

\section{References}

1. Boffetta P, Hashibe M. Alcohol and cancer. Lancet Oncol 2006; 7: 149-56.

2. Poschl G, Seitz HK. Alcohol and cancer. Alcohol Alcohol 2004; 39: 155-65.

3. Mathew A, Devesa SS, Fraumeni JF Jr, Chow WH. Global increases in kidney cancer incidence, 1973-1992. Eur J Cancer Prev 2002; 11: 171-8.

4. Tobacco smoke and involuntary smoking. IARC Monogr Eval Carcinog Risks Hum 2004; 83: 1-1438.

5. Pischon T, Lahmann PH, Boeing $\mathrm{H}$, et al. Body size and risk of renal cell carcinoma in the European Prospective Investigation into Cancer and Nutrition (EPIC). Int J Cancer 2006; 118: 728-38.

6. McLaughlin JK, Lipworth L, Tarone RE. Epidemiologic aspects of renal cell carcinoma. Semin Oncol 2006; 33: 527-33.

7. Brownson RC. A case-control study of renal cell carcinoma in relation to occupation, smoking, and alcohol consumption. Arch Environ Health 1988; 43: 238-41.

8. Kreiger N, Marrett LD, Dodds L, Hilditch S, Darlington GA. Risk factors for renal cell carcinoma: results of a population-based case-control study. Cancer Causes Control 1993; 4: 101-10. 
9. Maclure M, Willett W. A case-control study of diet and risk of renal adenocarcinoma. Epidemiology 1990; 1 430-40.

10. McLaughlin JK, Gao YT, Gao RN, et al. Risk factors for renalcell cancer in Shanghai, China. Int J Cancer 1992; 52: 562-5.

11. Yu MC, Mack TM, Hanisch R, Cicioni C, Henderson BE. Cigarette smoking, obesity, diuretic use, and coffee consumption as risk factors for renal cell carcinoma. J Natl Cancer Inst 1986; 77: 351-6.

12. Benhamou S, Lenfant MH, Ory-Paoletti C, Flamant R. Risk factors for renal-cell carcinoma in a French case-control study. Int J Cancer 1993; 55: 32-6.

13. Pelucchi C, La Vecchia C, Negri E, Talamini R, Franceschi S. Alcohol drinking and renal cell carcinoma in women and men. Eur J Cancer Prev 2002; 11: 543-5.

14. Schmidt W, De Lint J. Causes of death of alcoholics. Q J Stud Alcohol 1972; 33: 171-85.

15. Pell S, D'Alonzo CA. A five-year mortality study of alcoholics. J Occup Med 1973; 15: 120-5.

16. Monson RR, Lyon JL. Proportional mortality among alcoholics. Cancer 1975; 36: 1077-9.

17. Jensen OM. Cancer morbidity and causes of death among Danish brewery workers. Int J Cancer 1979; 23: 454-63.

18. Adami HO, McLaughlin JK, Hsing AW, et al. Alcoholism and cancer risk: a population-based cohort study. Cancer Causes Control 1992; 3: 419-25.

19. Nicodemus KK, Sweeney C, Folsom AR. Evaluation of dietary, medical and lifestyle risk factors for incident kidney cancer in postmenopausal women. Int J Cancer 2004; 108: 115-21.

20. Mahabir S, Leitzmann MF, Virtanen MJ, et al. Prospective study of alcohol drinking and renal cell cancer risk in a cohort of finnish male smokers. Cancer Epidemiol Biomarkers Prev 2005; 14: 170-5.

21. Rashidkhani B, Akesson A, Lindblad P, Wolk A. Alcoho consumption and risk of renal cell carcinoma: a prospective study of Swedish women. Int J Cancer 2005; 117: 848-53.

22. Lee JE, Giovannucci E, Smith-Warner SA, et al. Total fluid intake and use of individual beverages and risk of renal cell cancer in two large cohorts. Cancer Epidemio Biomarkers Prev 2006; 15: 1204-11.

23. Setiawan VW, Stram DO, Nomura AM, Kolonel LN Henderson BE. Risk factors for renal cell cancer: the multiethnic cohort. Am J Epidemiol 2007; 166: 932-40.

24. Lee JE, Hunter DJ, Spiegelman D, et al. Alcohol intake and renal cell cancer in a pooled analysis of 12 prospective studies. J Natl Cancer Inst 2007; 99: 801-10.

25. Greenland S. A meta-analysis of coffee, myocardial infarction, and coronary death. Epidemiology 1993; 4: 366-74.

26. DerSimonian R, Laird N. Meta-analysis in clinical trials. Control Clin Trials 1986; 7: 177-88.

27. Higgins JP, Thompson SG, Deeks JJ, Altman DG. Measuring inconsistency in meta-analyses. BMJ 2003; 327: 557-60.

28. Egger M, Davey Smith G, Schneider M, Minder C. Bias in meta-analysis detected by a simple, graphical test. BM 1997; 315: 629-34.

29. Begg CB, Mazumdar M. Operating characteristics of a rank correlation test for publication bias. Biometrics 1994; 50: 1088-101.

30. Goodman MT, Morgenstern H, Wynder EL. A case-control study of factors affecting the development of renal cell cancer. Am J Epidemiol 1986; 124: 926-41.

31. Wolk A, Gridley G, Niwa S, et al. International renal cell cancer study. VII. Role of diet. Int J Cancer 1996; 65: 67-73.

32. Yuan JM, Gago-Dominguez M, Castelao JE, et al Cruciferous vegetables in relation to renal cell carcinoma. Int J Cancer 1998; 77: 211-6.
33. Mattioli S, Truffelli D, Baldasseroni A, et al. Occupational risk factors for renal cell cancer: a case - control study in northern Italy. J Occup Environ Med 2002; 44: 1028-36.

34. Parker AS, Cerhan JR, Lynch CF, Ershow AG, Cantor KP. Gender, alcohol consumption, and renal cell carcinoma. Am J Epidemiol 2002; 155: 455-62.

35. Greving JP, Lee JE, Wolk A, et al. Alcoholic beverages and risk of renal cell cancer. Br J Cancer 2007; 97: 429-33.

36. Hsu CC, Chow WH, Boffetta P, et al. Dietary risk factors for kidney cancer in Eastern and Central Europe. Am J Epidemiol 2007; 166: 62-70.

37. Hu J, Chen Y, Mao Y, Desmeules M, Mery L. Alcohol drinking and renal cell carcinoma in Canadian men and women. Cancer Detect Prev 2008; 32: 7-14.

38. Pelucchi C, Galeone C, Montella M, et al. Alcohol consumption and renal cell cancer risk in two Italian casecontrol studies. Ann Oncol 2008; 19: 1003-8.

39. Benedetti A, Parent ME, Siemiatycki J. Lifetime consumption of alcoholic beverages and risk of 13 types of cancer in men: results from a case-control study in Montreal. Cancer Detect Prevent 2009; 32: 352-62.

40. Hu JF, Mao Y, DesMeules M, et al. Total fluid and specific beverage intake and risk of renal cell carcinoma in Canada. Cancer Epidemiol 2009; 33: 355-62.

41. Brock KE, Gridley G, Chiu BC, et al. Dietary fat and risk of renal cell carcinoma in the USA: a case-control study. $\mathrm{Br}$ J Nutr 2009; 101: 1228-38.

42. Asal NR, Risser DR, Kadamani S, et al. Risk factors in renal cell carcinoma: I. Methodology, demographics, tobacco, beverage use, and obesity. Cancer Detect Prev 1988; 11: 359-77.

43. McLaughlin JK, Mandel JS, Blot WJ, et al. A populationbased case-control study of renal cell carcinoma. J Natl Cancer Inst 1984; 72: 275-84.

44. Talamini R, Baron AE, Barra S, et al. A case-control study of risk factor for renal cell cancer in northern Italy. Cancer Causes Control 1990; 1: 125-31.

45. Mellemgaard A, Engholm G, McLaughlin JK, Olsen JH. Occupational risk factors for renal-cell carcinoma in Denmark. Scand J Work Environ Health 1994; 20: 160-5.

46. Lindblad P, Wolk A, Bergstrom R, Adami HO. Diet and risk of renal cell cancer: a population-based case-control study. Cancer Epidemiol Biomarkers Prev 1997; 6: 215-23.

47. Hu J, Mao Y, White K. Diet and vitamin or mineral supplements and risk of renal cell carcinoma in Canada. Cancer Causes Control 2003; 14: 705-14.

48. Mellemgaard A, Engholm G, McLaughlin JK, Olsen JH. Risk factors for renal cell carcinoma in Denmark. I. Role of socioeconomic status, tobacco use, beverages, and family history. Cancer Causes Control 1994; 5: 105-13.

49. McLaughlin JK, Lipworth L. Epidemiologic aspects of renal cell cancer. Semin Oncol 2000; 27: 115-23.

50. Li JJ, Hou X, Banerjee SK, et al. Overexpression and amplification of c-myc in the Syrian hamster kidney during estrogen carcinogenesis: a probable critical role in neoplastic transformation. Cancer Res 1999; 59: 2340-6.

51. Ginsburg ES. Estrogen, alcohol and breast cancer risk. J Steroid Biochem Mol Biol 1999; 69: 299-306.

52. Cauley JA, Gutai JP, Kuller LH, LeDonne D, Powell JG. The epidemiology of serum sex hormones in postmenopausa women. Am J Epidemiol 1989; 129: 1120-31.

53. Longnecker MP, Tseng M. Alcohol, hormones, and postmenopausal women. Alcohol Health Res World 1998; 22: $185-9$.

54. Gerhauser C. Beer constituents as potential cancer chemopreventive agents. Eur J Cancer 2005; 41: 1941-54. 
55. Goswami SK, Das DK. Resveratrol and chemoprevention. Cancer Lett 2009; 284: 1-6.

56. Bergstrom A, Hsieh CC, Lindblad P, et al. Obesity and renal cell cancer - a quantitative review. Br J Cancer 2001; 85: 984-90.

57. Lindblad P, Chow WH, Chan J, et al. The role of diabetes mellitus in the aetiology of renal cell cancer. Diabetologia 1999; 42: 107-12.

58. Davies MJ, Baer DJ, Judd JT, et al. Effects of moderate alcohol intake on fasting insulin and glucose concentrations and insulin sensitivity in postmenopausal women: a randomized controlled trial. JAMA 2002; 287: 2559-62. 